\title{
Institucionalistas e pós-keynesianos - ensaio sobre incerteza em uma economia capitalista financeira moderna *
}

\author{
Octavio A. C. Conceição **** \\ Carlos Roberto Gabriani ${ }^{\text {**** }}$
}

\section{Resumo}

Na evolução das ideias propostas por Keynes sobre uma economia monetária de produção, há ainda um fecundo campo para o desenvolvimento das análises sobre o comportamento das economias capitalistas financeiramente modernas que emerge de mediações entre os approaches teóricos institucionalista e pós-keynesiano. Tais abordagens são capazes de propiciar explicações mais aquilatadas sobre a natureza eminentemente instável do atual estágio do sistema capitalista. O conceito de incerteza é central nesta aproximação teórica. Na vertente institucionalista ela decorre do processo natural de co-evolução das instituições econômicas e sociais e afeta as relações com os indivíduos ("processo de causação"). Nos pós-keynesianos, ela gera indefinições na tomada de decisões dos agentes econômicos, incapazes de prever o comportamento futuro da economia. Daí que, segundo Minsky, emana o imperativo de ações coordenadas de intervenções, tanto por parte do Estado quanto pela sociedade, com vistas a criar instituições, capazes de atenuar ou agravar o percurso da trajetória do sistema econômico.

Palavras-chave: Intitucionalismo; Pós-keynesiano; Incerteza.

\begin{abstract}
Institutionalists and Post-Keynesians - essay on uncertainty in modern financial capitalist economies

Keynes's ideas on the monetary economy of production is a fecund field of analysis to understand the current behavior of modern financial capitalist economies, as a result of the confluence between institutionalist and postKeynesian theoretical approaches. In this theoretical amalgam, the concept of uncertainty assumes a central role, making it possible to analyze more accurately the eminent unstable nature of the current stage of development of such economies. In the institutionalist aspect, uncertainty results from the natural and co-evolutionary process of economic and social institutions and their relations with individuals ("process of circular causation"), while in the post-Keynesian conception, uncertainty generates imprecision in decision-making, which make it difficult to predict the future behavior of the economy. For Minsky, this implies the imperative of coordinated interventions by the state and by society in order to create institutions capable of mitigating the trajectory of the economic system.
\end{abstract}

Keywords: Institutionalism; Post-Keynesian; Uncertainty.

JEL B25, B22, B50.

\section{Introdução}

Tanto para a escola institucionalista norte-americana quanto para o approach teórico pós-keynesiano, sobretudo na abordagem de Minsky, a incerteza tem um papel fundamental na

\footnotetext{
${ }^{*}$ Artigo recebido em 20 de janeiro de 2017 e aprovado em 25 de setembro de 2017.

** Professor Titular da Universidade Federal do Rio Grande do Sul (UFRGS), Porto Alegre, RS, Brasil.

**** Membro permanente do Programa de Pós-Graduação em Economia e do Departamento de Economia e Relações Internacionais da Faculdade de Ciências Econômicas da UFRGS. E-mail: octavio@ufrgs.br.

${ }^{* * * *}$ Professor Adjunto do Curso de Ciências Econômicas, da Universidade Federal de Mato Grosso do Sul. E-mail: carlos.gabriani@ufms.br.
} 
determinação do funcionamento de uma moderna economia capitalista financeira. Ela afeta o comportamento dos agentes e o processo de tomada de decisões. Essa é a razão que leva o sistema produtivo capitalista a um comportamento inerentemente instável, sujeitando-o a crises financeiras profundas, o que impõe a necessidade de ação coordenada pelo Estado. Tal mecanismo, dependendo da forma como é ou não empregado, pode aprofundar ou atenuar os efeitos críticos sobre o sistema, refletindo-se nas decisões e ações dos agentes econômicos. Tal nexo aproxima as abordagens institucionalistas e pós-keynesianas.

O ensaio está dividido em três seções. Na primeira se faz uma incursão acerca da importância do pensamento institucionalista, que inclui os aportes de minskyanos. Na segunda, analisa-se as relações entre probabilidade, convenção e incerteza em Minsky, objetivando estabelecer as bases da mediação teórica entre o approach pós-keynesiano e o institucionalista. $\mathrm{Na}$ terceira seção, discute-se as relações entre a incerteza no estágio atual do desenvolvimento capitalista - denominado por Minsky de "capitalismo gestor do dinheiro" - e a necessidade de criação de instituições que possam atenuar os efeitos da crise daí oriunda.

\section{Aspectos da compatibilidade da abordagem institucionalista com a visão de Minsky}

O período de fortes turbulências econômicas que as economias modernas têm atravessado desde a eclosão de crise financeira de 2008, trouxe à tona "velhas" e defensáveis ideias, que o mainstream neoclássico, tão vigoroso nas últimas duas décadas e meia, insistiu em ofuscar, desqualificar e omitir, simplesmente por fugir da elegância formal dos modelos matemáticos, cuja hegemonia parecia ter triunfado. Alertas das correntes não ortodoxas não ecoavam nas míopes concepções econômicas ortodoxas, em especial as advertências recorrentes de Hyman Minsky, sobre a iminência de um grande colapso financeiro mundial. O mainstream sempre se deixou dominar pelas noções de racionalidade substantiva, pelos fundamentos de otimalidade macroeconômica e pelas expectativas racionais dos agentes, que tudo acomodavam. Sob esses pressupostos garantia-se, assim, um ambiente de estabilidade "solidamente" ancorado nas condições de longo prazo, forjado em seus próprios fundamentos doutrinários. A gravidade da crise que se sucedeu concedeu um dramático triunfo às concepções de Keynes, dos pós-keynesianos e, em especial, aos estudos de Hyman Minsky, que passou a ser respeitado como visionário, sem o mesmo jamais ter reivindicado tal pretensão, senão o de entender a dinâmica das economias capitalistas contemporâneas.

O aprofundamento dos efeitos da crise em 2008 revigorou o olhar keynesiano sobre as dinâmicas das economias capitalistas, sugerindo a novidade e "surpreendente" atualidade de seus ensinamentos, os quais, na longínqua década de 30 - que parecia sepultada, porque "superada" historicamente -, explicitavam, com notável clareza, a dimensão da atual crise financeira. Os mercados exigiam intervenção estatal para garantir, através de seus mecanismos de ação coletiva, o retorno à prosperidade para superação da crise. Isto pouco tem a ver - ou deixou de ter - com gastança estatal generalizada e muito menos com o temor inflacionário, que, até então, constituía, para a maioria dos críticos ao keynesianismo, e equivocadamente, a essência de sua teoria. Reivindica-se, atualmente, uma revisão da desregulamentação dos 
Institucionalistas e pós-keynesianos - ensaio sobre incerteza em uma economia capitalista financeira moderna

mercados e uma feroz disciplina financeira comandada pelo Estado, agora chamado a organizar o caos financeiro.

A crise atual decorreu do esgotamento da fase anterior de prosperidade econômica, que persistiu desde meados dos anos 80 até meados da primeira década do Século XXI, liderada pelos Estados Unidos, seguida pelas maiores economias europeias, além de China e Japão, que, sob a égide da liberalização e flexibilização dos mercados, imprimiram notável vigor à financeirização do capital e à liberalização financeira global. Do ponto de vista produtivo e tecnológico, tal articulação foi comandada pela microeletrônica, pela indústria da informática e setores afins, em uma engrenagem tecno-econômica, que os neo-schumpeterianos ${ }^{1}$ designaram de "paradigma tecnológico da informação". Tal paradigma, por sua vez, sucedera o paradigma da produção em massa, também designado genericamente de fordismo, que se esgotara em meados dos anos $60^{2}$.

O que permitiu esse relativamente longo período de prosperidade? Vários fatores concorreram para isso, mas não é objetivo desse texto explorá-los. O que é notório destacar é que foi gestado, nessa etapa, um importante período de crescimento econômico, cujas raízes encontram-se na montagem de um processo tecnológico, institucional e consequentemente econômico, que apresenta sinais de esgotamento.

A questão que se recoloca nos dias de hoje é quais escolas contemplam esta dimensão analítica que procura dar conta das instabilidades, intrínsecas ao sistema econômico, e sua superação. Inequivocamente, a história do pensamento econômico novamente nos evidencia que a contribuição de autores como Marx, Keynes, Schumpeter (e até dos Clássicos, como Smith, Ricardo, Malthus, e neoclássicos como Marshall) contém elementos para captar a essência deste processo. A convergência entre elas reside no entendimento de como operam as mudanças estruturais no mecanismo de funcionamento do sistema econômico. Para eles, seria impossível compreender a natureza e a dinâmica do processo de crescimento capitalista sem compreendermos o tipo de mudanças envolvidas entre uma etapa de crescimento e outra. Tal perspectiva analítica também ecoa densamente na convergência do pensamento institucionalista com a contribuição pós-keynesiana. É disso que será tratado na sequência.

\subsection{Os antecedentes do pensamento institucionalista}

John Commons, famoso institucionalista norte-americano, já no início da década de 30 chamava atenção sobre a dificuldade em se definir a economia institucional. À medida que seu reconhecimento avançava, persistiam dúvidas sobre o significado da economia institucional.

(1) Por neo-schumpeterianos incluímos toda a tradição herdeira do legado schumpeteriano da ênfase na dinâmica da inovação e da mudança tecnológica. Seus principais expoentes são Nelson e Winter (1982), Dosi (1988), Freeman (1995) e Perez (1989).

(2) O termo fordismo foi criado, nos anos 80 , pela denominada escola francesa da regulação, que, na época, ocupava-se com a explicação da natureza da crise do "fordismo". Para eles, seriam as "formas institucionais de estrutura" que constituiriam o principal instrumento conceitual para distinguir as fases de crise e restauração econômica. Alguns de seus expoentes foram Aglietta, Lipietz, Boyer e Coriat. 
Tal dificuldade decorria da própria ambiguidade do termo: às vezes instituição parecia ser uma estrutura de leis e direitos naturais dentro da qual os indivíduos agem como condôminos; outras vezes instituição figurava como o próprio comportamento dos condôminos. Até hoje persiste esta dicotomia analítica separando, de forma bastante nítida, o "novo" institucionalismo da NEI, do antigo ou "original" institucionalismo de Veblen.

Para superar tal limitação, John Commons, em seu texto clássico de 1931, fornecia uma pista, afirmando que tal definição só se tornaria precisa mediante a constituição de uma teoria econômica das instituições. O moderno pensamento institucionalista em suas variantes "antigas" ou "novas" continuam travando embates nesse campo, os quais, apesar de notáveis avanços teóricos e analíticos, continuam a exigir a constituição de uma formulação teórica mais precisa.

A tradição institucionalista herdeira de Veblen, Commons e Mitchell trouxe novos conceitos sem, entretanto, deixar de preservar os traços que lhe são distintivos do pensamento neoclássico. Contudo, a compatibilidade com o pensamento de Marx, Keynes e Schumpeter permanece, em muitos aspectos, sustentável. A amplitude e complexidade do pensamento institucionalista, não podendo ser patrimônio de uma única e exclusiva "visão", confere à teia de múltiplas concepções a possibilidade de se avançar em direção a uma teoria da dinâmica das instituições.

O institucionalismo é uma linha de pensamento oposta ao neoclassicismo (HODGSON, 1998b), semelhante ao marxismo em alguns aspectos (DUGGER, 1988) e vinculada ao evolucionismo (Hodgson, 1993). Independentemente do enfoque adotado, atribuise ao "velho" institucionalismo norte-americano, a partir dos escritos de Veblen - e em menor grau de Commons (1934) e de Mitchell (1984) -, a matriz da Escola Institucionalista. Seu núcleo de pensamento relaciona-se aos conceitos de instituições, hábitos, regras e sua evolução, explicitando forte vinculação das especificidades históricas com a abordagem evolucionária. A constituição de uma teoria econômica com instituições, oriunda da relação entre a atividade humana, as instituições e a natureza evolucionária do processo econômico, definiria diferentes tipos de economia. Assim, se fosse possível afirmar que existe uma "teoria geral" institucionalista, sua generalidade seria indicar como desenvolver análises específicas e variadas, em relação a um fenômeno específico. É nesse aspecto que se considera a semelhança com o pensamento keynesiano. Isto porque é a partir da vigência de incerteza, do caráter não neutro da moeda e de sua influência sobre as decisões e hábitos dos agentes, que se estabelece uma articulação institucional, que responde pela difusão ou não do processo de crescimento econômico.

O velho institucionalismo de Thorstein Veblen, John Commons e Wesley Mitchel centra sua análise na importância das instituições, reivindicando uma genuína economia evolucionária, em que a evolução das instituições torna-se elemento condicional do desenvolvimento econômico e social. Entretanto, desenvolveram uma linha analítica mais descritiva, deixando para um segundo plano questões teóricas não-resolvidas. Em razão disso, 
Institucionalistas e pós-keynesianos - ensaio sobre incerteza em uma economia capitalista financeira moderna

alguns simpatizantes, como Gunnar Myrdal (1953), qualificam o antigo institucionalismo americano de "empirismo ingênuo", o que, de forma alguma, inviabilizou seu legado. E esse é precisamente o ponto que torna os institucionalistas evolucionários, pois a negação de pensar a economia em torno da noção de equilíbrio, ou ajustamento marginal, reitera a importância do processo de mudança e transformação, ambos implícitos no pensamento de Veblen. Sua abordagem tem três pontos centrais: o primeiro refere-se ao tratamento, inadequado, dado pela teoria neoclássica à questão das inovações, supondo-as dadas e acessíveis, desconsiderando as condições de sua implantação; o segundo relaciona-se à sua preocupação não com o equilíbrio estável e de otimalidade, mas em como se dá a mudança e o consequente crescimento e, em terceiro, há uma ênfase no processo de evolução econômica e transformação tecnológica. Nesse sentido, o conceito de instituição é definido como sendo resultado de uma situação presente, que molda o futuro, através de um processo seletivo e coercitivo, orientado pela forma como os homens veem as coisas, o que altera ou fortalece seus pontos de vista.

A reiterada crítica ao pensamento neoclássico persiste pelo fato de o mesmo ter por pressuposto uma falsa concepção da natureza humana. O indivíduo é equivocadamente visto em termos hedonísticos, sendo um ente socialmente passivo, inerte e imutável (Veblen, 1919, p. 73). Tal hipótese, veementemente rejeitada por Veblen, estabelece como alternativa a tentativa de construir uma "teoria econômica evolucionária" onde instintos, hábitos e instituições exercem na evolução econômica papel análogo aos genes na biologia (Veblen, 1899, p. 190-191 apud Hodgson, 1993, p. 17). Isto significa que linhas de ação habituais definem pontos de vista, através dos quais os fatos e os eventos são percebidos. Como são as instituições sociais, a cultura e as rotinas que dão origem a certas formas de seleção e compreensão dos dados, estabelece-se daí importante vínculo entre o pensamento evolucionário com as concepções de Veblen sobre o papel das instituições.

O clássico artigo de Veblen Why is economics not an evolutionary science? Escrito em 1898, apesar de sugerir no título o caráter não-evolucionário da economia, revela muita proximidade com o referido pensamento. Já em 1919, Veblen salientava que a história da vida econômica dos indivíduos constituía-se em um "processo cumulativo de adaptação dos meios aos fins, que, cumulativamente, modificavam-se, enquanto o processo avançava". Isto implica reconhecer que Veblen adotou uma posição pós-darwiniana, enfatizando o caráter de "processo de causação" tão comum na concepção evolucionária. Veblen escreveu em 1899, que "a vida do homem em sociedade, assim como a vida de outras espécies, é uma luta pela existência e, consequentemente, é um processo de seleção adaptativa. A evolução da estrutura social tem sido um processo de seleção natural de instituições" (Veblen, 1899 apud Hodgson, 1993a, p. 17). Este processo de seleção ou coerção institucional não implica que as instituições sejam imutáveis ou rígidas. Pelo contrário, elas mudam e, mesmo através de mudanças graduais, podem pressionar o sistema por meio de explosões, conflitos e crises, levando a mudanças de atitudes e ações. Em qualquer sistema social há uma permanente tensão entre ruptura e regularidade, exigindo constante reavaliação de comportamentos rotinizados e decisões voláteis de outros agentes. Mesmo podendo persistir por longos períodos, está igualmente 
sujeita a súbitas rupturas e consequentes mudanças nos hábitos de pensar e agir, que são cumulativamente reforçados.

A ideia de evolução em Veblen está intimamente associada à de "processo de causação circular", podendo ter sido, segundo Hodgson (1993a), o precursor dos estudos realizados por Allyn Young, Gunnar Myrdal, Nicholas Kaldor e K. William Kapp. A complexidade das ideias de Veblen o credencia a estar incluído entre os grandes nomes do pensamento econômico, como Marx, Marshall, Keynes e Schumpeter. Igualmente poderia figurar entre os principais expoentes da "moderna economia evolucionária", uma vez que seu programa de pesquisa, assim como o de Schumpeter, procurava implicitamente explorar a aplicação de ideias da biologia às ciências econômicas. Isto, segundo Hodgson (1993), torna Veblen um evolucionário, o que permite designar seu pensamento como institucionalismo evolucionário. ${ }^{3}$

Genericamente, pode-se afirmar que se, por um lado, não há no antigo pensamento institucionalista norte-americano uma teoria econômica propriamente dita, o que há são postulados genéricos e princípios analíticos de oposição ao neoclassicismo, sugerindo forte vinculação de análises históricas com especificidades locais. Isto gerou um amplo campo de investigação teórica que as escolas que se formaram, a partir dos anos 60, trataram de dar substância teórica mais consistente. Essa foi a razão do revigoramento do interesse em discussões de temas institucionalistas materializadas no grande sucesso da Nova Economia Institucional (NEI) dos anos 60 e dos menos famosos neo-institucionalistas (seguidores modernos de Veblen), que recolocaram a necessidade de se aprofundar algumas noções propostas por Veblen.

\subsection{Aspectos de uma Teoria Institucionalista}

O embate teórico entre institucionalistas e ortodoxia acompanhou a evolução do pensamento econômico ao longo de praticamente todo o século $\mathrm{XX}^{4}$. Aos primeiros, principalmente os herdeiros do pensamento vebleniano, caberia enfatizar os aspectos essenciais à constituição de um campo analítico genuinamente teórico; e aos últimos, onde se incluem

(3) Segundo Samuels (1995): 'The term 'institutional economics' is used without prejudice to 'evolutionary economics'. Isto porque ambos são unidos por um campo de pesquisa comum: "all have an interest in topics that are institutionalist in substance and have no particular interest in contributing to the neoclassical paradigm. Some are specialists in particular areas of study, such as evolutionary analysis, organisation theory, and technology. These subjects require, as they see it, modes and methods of analysis often quite different from, though not necessarily totally in conflict with, neoclassical approaches to their subject. These modes and methods of analysis are more congruent with those of the US institutionalists, although they sometimes use tools and concepts originally developed by neoclassicists, such as transaction costs" (Samuels, 1995, p. 576-577).

(4) Segundo Beaud e Dostaler (2000), "O pós-guerra foi marcado pela afirmação da heterodoxia pós-keynesiana, pela permanência do institucionalismo (enriquecido pelos contributos de pensadores singulares como Myrdal, Perroux e Galbraith, mas também Coase e H. Simon) e pela renovação dos marxismos. Os principais debates centraram-se em torno da análise do crescimento e do capital, da leitura das transformações do capitalismo contemporânea e da questão do desenvolvimento" (Beaud; Dostaler, 2000, p. 109). Tais autores "esforçaram-se por lançar as bases de teorias alternativas à teoria neoclássica; tal como Keynes relativamente ao desemprego dos anos trinta, também eles tinham a preocupação de, afim de contribuírem para encontrar soluções para os problemas mundiais (pobreza, desigualdades, dinâmicas desiguais, atentados aos recursos não-renováveis e ao meio ambiente), construir um quadro explicativo adequado" (Beaud; Dostaler, 2000, p. 117). 
Institucionalistas e pós-keynesianos - ensaio sobre incerteza em uma economia capitalista financeira moderna

autores como Schumpeter, Coase e Williamson, há uma reiterada insistência na fragilidade teórica do denominado institucionalismo. Segundo Williamson, a ausência de um campo analítico teórico condenaria, como acabou condenando no pós-30, o institucionalismo ao esquecimento ou ao fogo. Esta ilação caracterizou a battle of methods a que se referia Schumpeter nos anos 40, levando o institucionalismo à designada "letargia decenal" (Hodgson, 1993).

O reconhecimento do institucionalismo como teoria ${ }^{5}$ começa a tomar forma no início dos anos 60, coincidindo com a crise do keynesianismo bastardo e com a (re)ascensão do neoclassicismo, que assumia um caráter crescentemente hegemônico. Sob este manto revigorase o institucionalismo, só que não mais sob o desígnio de um "empirismo ingênuo" (como designou Myrdal), que estaria condenado ao ostracismo, mas sim através de uma efetiva roupagem teórica, na esteira da fronteira do hard core neoclássico, que, incorporando e reconhecendo a importância das instituições (Matthews, 1986), as inclui no arcabouço teórico do mainstream sob um outro rótulo. No lugar do empirismo ingênuo, historicista descritivo e a-teórico formavam-se os fundamentos do que passou a ser designado Nova Economia Institucional (NEI). "Nova" em oposição ao legado teoricamente "vazio de cientificidade" da "velha" vertente vebleniana, e "Economia Institucional" como um novo campo teórico finalmente desvendado e revelado pelos avanços do pensamento neoclássico, que, afinal, incorporara as instituições. O sucesso e méritos da referida escola de pensamento são por demais reconhecidos e inquestionáveis. Permitiram reviravoltas teóricas relevantes como a constituição de um novo tratamento analítico à Teoria da Firma, que sepultou a lógica do princípio otimizador como comportamento predominante e estabeleceu novos nexos teóricos com estratégias de sobrevivências, comportamento diferenciado dos agentes (ora como imitadores, ora inovadores, ora refratários às mudanças), etc. Estabeleceu também novos cânones à compreensão do processo de desenvolvimento econômico que passou a ser crescentemente guiado pela forma como se estabeleciam as regras (formais e informais), que, anos depois, passaram a orientar as mudanças institucionais, verdadeira responsável pela performance dos países (North, 1994, 2005).

Contudo, pode-se afirmar com convicção que assim como o keynesianismo bastardo, sedimentado a partir das interpretações de Hicks $(1936,1937,1939)$ e das visões das duas Cambridge sobre as políticas econômicas keynesianas (ver Beaud; Dostaler, 2000, especificamente o capítulo 5), está para a economia de Keynes, a Nova Economia Institucional está para o "velho" ou "original" institucionalismo vebleniano.

Assim, há um campo teórico em economia institucional que veio se formando ao longo do tempo e consolidou-se recentemente como um domínio analítico evolucionário, cujos principais pontos residem na crítica ao mainstream, na importância do processo histórico, na predominância de incerteza, e na natureza desequilibrada da atividade capitalista que serão explicitados a seguir.

(5) Saliente-se que sequer os livros manuais de HPE incluíam Veblen como linhas de pensamento no pós 40. 


\subsection{A abordagem neo-institucionalista (ou institucionalismo contemporâneo)}

A abordagem neo-institucionalista é derivada da forte influência de Veblen, resgatando a importância de conceitos centrais ao Antigo Institucionalismo Norte-americano, e do crescente vigor teórico da tradição neo-schumpeteriana. Alguns pressupostos definem seu conteúdo: primeiro, a economia é vista como um "processo contínuo", que se opõe às hipóteses da economia ortodoxa, na qual a "economia positiva" não se relaciona com tempo, lugar e circunstâncias; segundo, as interações entre instituições, tecnologia e valores são fundamentais; terceiro, a análise econômica ortodoxa é rejeitada por ser demasiadamente dedutiva, estática e abstrata, constituindo-se mais em celebração das instituições econômicas dominantes do que uma procura pela verdade e justiça social; e quatro, os institucionalistas enfatizam aspectos ignorados por muitos economistas ortodoxos, como os trabalhos empíricos e teóricos de outras disciplinas, que lhe conferem um caráter multidisciplinar, ou seja, reconhecem a importância de interesses e conflitos, a mudança tecnológica e a inexistência de uma constante (como, por exemplo, a velocidade da luz) aplicável à vontade humana, o que torna difícil compreender a economia como uma "teoria positiva" (Marshall, 1993, p. 302).

Portanto, importa à economia institucionalista o processo histórico na formulação das ideias e das políticas econômicas. Samuels (1995) vê a "economia institucional" como uma alternativa não-marxista ${ }^{6}$ ao neoclassicismo dominante no mainstream, caracterizado por uma variedade de abordagens que podem ser aglutinadas segundo alguns pontos de confluência. A proposição de um "paradigma institucionalista", sugerida por alguns autores, visa identificar os elementos e crenças comuns, que operam em níveis teóricos e práticos semelhantes, sem, entretanto, deixar de distinguir as várias aplicações específicas. O primeiro ponto desta abordagem é o do papel do mercado como mecanismo guia da economia, ou a concepção da economia enquanto organizada e orientada pelo mercado. Para os institucionalistas - que questionam a escassez de recursos alocada entre usos alternativos pelo mercado - quem determina a real alocação em qualquer sociedade é sua estrutura organizacional, que é, em resumo, dada por suas instituições, sendo o mercado quem dá cumprimento às instituições predominantes.

Os institucionalistas se preocupam com a organização e controle da economia, enquanto sistema mais abrangente e complexo do que o mercado. ${ }^{7}$ Isto implica reconhecer a importância de vários aspectos como: a distribuição de poder na sociedade; a forma de

(6) Mesmo reiterando o caráter não-marxista do pensamento institucionalista, Samuels (1995) acredita não ser uma linha mutuamente exclusiva em relação a esta concepção. Para ele: "Some institutionalists consider their approach to be mutually exclusive with neoclassicism, whereas others, including this writer, consider institutionalism and neoclassicism to be supplementary. Some institutionalists consider their approach to be mutually exclusive with Marxism, whereas others, including this writer, consider institucionalism and Marxism as having significant areas of overlap. There has been considerable diversity within institutional economics. Such heterogeneity is not pathological. It is a sign of richness and ferment" (Samuels, 1995, p. 570).

(7) Isso de certo modo está relacionado com as preocupações e, sobretudo, recomendações de Minsky (1986) referentes à necessidade do Estado em dar cumprimento às intervenções para antepor-se às panaceias resultantes das crises financeiras associadas à forma de organização institucional desse setor econômico. 
Institucionalistas e pós-keynesianos - ensaio sobre incerteza em uma economia capitalista financeira moderna

operação dos mercados (enquanto complexos institucionais em interação uns com os outros); a formação de conhecimento (ou o que leva ao conhecimento em um mundo de radical indeterminação sobre o futuro); e a determinação da alocação de recursos (nível de renda agregada, distribuição de renda, organização e controle), onde a cultura geral também importa (Samuels, 1995, p. 571).

Apesar das críticas, os institucionalistas reconhecem a notável contribuição dos neoclássicos quanto ao funcionamento do mercado. Entretanto, ela falha ao tratar os indivíduos como independentes, auto-subsistentes, com suas preferências dadas, o que decorre da própria limitação do individualismo metodológico. Para os institucionalistas, os indivíduos são, em realidade, cultural e mutuamente interdependentes. A crítica à natureza estática dos modelos neoclássicos reafirma a importância em se resgatar a natureza dinâmica e evolucionária da economia.

A partir desses elementos Samuels propõe um "paradigma institucionalista" centrado em três dimensões: na crítica à organização e performance das economias de mercado, por se constituírem em mera abstração na vertente ortodoxa; na geração de um substancial corpo de conhecimento em uma variedade de tópicos; e no desenvolvimento de um approach multidisciplinar para resolver problemas. Todas as abordagens, apesar de diferentes nuanças, aproximam-se do referido corpo de conhecimento, revelando um ponto em comum: a negação do funcionamento da economia como algo estático, regulado pelo mercado na busca do equilíbrio ótimo. A nosso ver, esses pontos estabelecem notável convergência com a visão póskeynesiana e com o aporte minskyano.

Embora persistam vários elementos teóricos que possam vir a obstaculizar a consolidação de uma definitiva teoria institucionalista, a contribuição dos neo-institucionalistas assinala para pontos fundamentais, que inserem as instituições em um ambiente evolucionário, permitindo aproximá-los do respectivo campo de pesquisa - que tem um corpo teórico consolidado - e resgatar pontos abrangentes sugeridos por Veblen, centrados na multidisciplinariedade, na importância dos conflitos e nos hábitos das pessoas. A complexa tarefa de avançar rumo à constituição de uma teoria institucionalista propriamente dita não pode prescindir do avanço nas linhas de pesquisa aí sugeridas. Considerou-se que, sob esta ampla agenda de pesquisa, a contribuição de autores como Minsky estabelece novas mediações institucionais, a respeito da compreensão da instável dinâmica financeira do capitalismo. São sobre estas mediações que se busca discutir nos próximos itens.

\section{Hyman Minsky: probabilidade ou convenção diante da incerteza?}

Entre os autores pós-keynesianos, Minsky é o que mais se aproxima do pensamento institucionalista norte-americano. Esta aproximação é decorrente da semelhança acerca da compreensão do funcionamento das economias capitalistas financeiras modernas, que Minsky designa "capitalismo gestor do dinheiro" (Money manager capitalism). Para os institucionalistas este conceito caracteriza um "arranjo institucional" historicamente 
constituído. Ambas as concepções fundam-se em Keynes, no que ele denomina "economia monetária de produção"

O comportamento de uma economia monetária de produção alterna-se entre períodos de booms e de fases recessivas. Esse comportamento, por sua vez, relaciona-se ao modo como os agentes econômicos tomam decisões relativas a gastos com investimento - componente da demanda efetiva com comportamento muito volátil, em razão de ser determinado com base em previsões intuitivas sobre fluxos de rendas futuros ${ }^{9}$. Ocorre que, sob a vigência de uma economia capitalista financeira moderna, a moeda, dada a sua essencialidade, conforme demonstrado por Keynes (1985), não é neutra. Isto implica reconhecer seu caráter ativo sobre as decisões dos agentes, que repercutirão sobre o animal spirit de todo o sistema. A ela estarão subordinadas decisões de progressão ou retração econômica e da consequente montagem de todo um sistema institucional emergente.

Diferentemente do pensamento ortodoxo, Keynes em A Teoria Geral do Emprego, do juro e da moeda, rompe com o axioma ortodoxo neoclássico da neutralidade da moeda segundo o qual a posse de moeda per se não proporciona nenhuma utilidade. A partir daí passa a enfatizar que a moeda, dada suas propriedades essenciais ${ }^{10}$, serve como um ativo que se diferencia dos demais por possuir liquidez absoluta e, por isso, proporciona a seu possuidor um prêmio. Neste sentido, a moeda passa a compor o portfólio de ativos, não por proporcionar aos seus proprietários possuidores um fluxo de renda, como os outros ativos ilíquidos ou reproduzíveis, mas por apresentar liquidez absoluta e servir de garantia quanto às incertezas futuras, o que faz os agentes econômicos demandar moeda per se. A demanda por moeda está relacionada aos motivos que levam os agentes econômicos a preferirem liquidez: transação, precaução, especulação e finance motive. Segundo Keynes (1985), os agentes demandam moeda diante da incerteza quanto ao futuro. Neste sentido, ao servir de segurança contra incertezas a moeda aproxima, através de contratos monetários, passado, presente e futuro, "coordenando, assim, a atividade econômica" (Ferrari Filho, Conceição, 2001, p. 102).

(8) Sobre economia monetária de produção ver Carvalho (1988) e Kregel (1998) e Kregel (1998, p. 111-133).

(9) Conforme Ferrari Filho e Conceição (2001), "é a existência de incerteza que explica a volatilidade do investimento e, por conseguinte, a racionalidade por preferência pela liquidez, ocasionando, assim, flutuações de demanda efetiva e desemprego" (Ferrari Filho; Conceição, 2001, p. 106). Os agentes econômicos retêm moeda diante da incerteza quanto ao futuro causando redução da demanda agregada com efeitos sobre as expectativas dos empresários e investidores quanto às decisões de produzir e investir e, portanto, quanto à quantidade de emprego demandar. Isto é o fator que torna possível, segundo Keynes (1985), o sistema econômico operar em equilíbrio com desemprego.

(10) Para Keynes (1985), a moeda apresenta as propriedades de uma elasticidade-produção zero e de elasticidadesubstituição negligenciável, ou nula. Isto quer dizer que ela não é produzida pela quantidade de trabalho que o setor privado incorpora no processo produtivo. Conforme destaca Davidson (1996), "Em essência, todos os ativos líquidos são não reproduzíveis pelo uso do trabalho no setor privado" (Davidson, 1996, p. 31). Isto quer dizer que a "moeda não cresce nas árvores"; portanto, "não pode ser produzida contratando-se trabalhadores desempregados [...] sempre que as pessoas demandarem manter ativos líquidos adicionais como reserva de valor" (Davidson, 1996, p. 31). Assim também, enquanto um ativo que proporciona segurança aos agentes diante da incerteza futura, ela não é substituída por outros ativos não líquidos. 
Institucionalistas e pós-keynesianos - ensaio sobre incerteza em uma economia capitalista financeira moderna

Além da não neutralidade da moeda, outra questão central em Keynes, para se entender as aproximações entre pós-keynesianos e institucionalistas, é a relação entre moeda e incerteza. A descrição da incerteza, e o processo de tomada de decisão sob tal condição, foi bem especificada no Tratado Sobre a Probabilidade onde Keynes estabelece as diferenças entre as probabilidades de uma proposição e o peso associado a uma proposição. Segundo o autor, existem vários graus de convicções racionais - ou "crenças", conforme denominação de Keynes - a respeito de uma proposição, que são definidas a partir do conhecimento que se dispõe em relação a prováveis eventos ou fenômenos futuros. Segundo Minsky (2011), "a visão de Keynes no Tratado Sobre a Probabilidade era de que o grau de convicção racional, ou probabilidade, associado a uma proposição, $a$, era condicional em relação aos indícios, $b[\ldots]$ escrita como: $a / b$ [ $a$, condicionado por $b$ ]" (Minsky, 2011, p. 85). Assim, embora em alguns casos como, por exemplo, em uma mesa de jogo honesto, "seja possível atribuir a $a / b$ um valor numérico exato compreendendo-se as circunstâncias objetivas, em outros casos, mais prevalecentes no mundo e mais pertinentes para a economia, critérios objetivos, com os quais observadores sofisticados podem concordar, não levam a nenhum valor numérico tão exato" (Minsky, 2011, p. 85). Não obstante isto, o autor segue afirmando que

[mesmo] em casos em que nenhum valor numérico preciso pode ser objetivamente atribuído, é preciso tomar decisões, e elas são tomadas como se alguma atribuição objetiva de probabilidade pudesse ser dada; poderíamos chamar esse tipo de probabilidades, atribuídas na ausência de conhecimento suficiente, de "probabilidades subjetivas". Essas probabilidades subjetivas, atribuídas com base em insuficiente conhecimento, estão sujeitas a mudanças rápidas e substanciais; da mesma forma, processos devidos a decisões baseadas nesse tipo de estimativas podem mudar rápida e acentuadamente (Minsky, 2011, p. 85).

No Tratado Sobre a Probabilidade Keynes também estabelece que além da probabilidade, objetiva ou subjetiva, atribuída a uma proposição condicional, $a / b$, existem outros fatores subjetivos que atuam na tomada de decisão dos agentes econômicos. Tais fatores subjetivos estão relacionados com "o peso ou a confiança com que a probabilidade atribuída [objetiva ou subjetiva] é usada como guia para a ação ou a decisão" (Minsky, 2011, p. 85). Neste sentido, a ocorrência de fenômenos econômicos pode afetar de maneira drástica o comportamento dos agentes levando-os a "mudar as distribuições de probabilidades subjetivas atribuídas a eventos futuros e aumentar ou diminuir a confiança com que são sustentadas as visões de mundo" (Minsky, 2011, p. 86). Isso permitiu a Keynes entender o problema da tomada de decisão em uma economia na qual as escolhas realizadas pelos agentes econômicos, sobretudo as relacionadas à composição do portfólio, são extremamente importantes, envolvendo não apenas o tempo, mas também a formação de expectativas quanto aos processos e eventos futuros. Dessa forma, Keynes sustentava ser impossível substituir incerteza por certeza equivalente, na forma de cálculo de um risco atuarial probabilístico definido ${ }^{11}$, e que as

(11) Keynes (1937) destaca claramente as diferenças entre sua concepção de incerteza em relação à concepção ortodoxa ao afirmar que para estes "em qualquer dado momento, pressupunha-se que fatos e expectativas seriam dados em uma forma definida e calculável; e os riscos que, admitamos, não foram muito notados deveriam ser capazes de passar por um cálculo atuarial exato. Supunha-se que o cálculo de probabilidade [...] fosse capaz de reduzir a incerteza para uma mesma situação calculável como a da certeza em si” (Keynes, 1937, p. 212-213). 
Octavio A. C. Conceição, Carlos Roberto Gabriani

proposições probabilísticas subjetivas relevantes, juntamente com seus pesos relativos, variam não ao acaso, ou de modo imprevisível, mas de maneira coerente em reação à ocorrência dos eventos, mudando em consonância e pari passu às mudanças verificadas nos processos e eventos.

É neste sentido que Skidelsky (1983), analisando os fundamentos da formação teórica de Keynes, destaca que "[...] [s] us interesses principales em economia procedían de sus trabajos sobre Probabilidad" (Skidelsky, 1983, p. 208) e, argumentando em relação ao ainda incipiente estágio de desenvolvimento de sua teoria financeira fundamentada num comportamento incerto e não probabilístico do agente investidor:

[...] le afectará, como es obvio, no la renta neta que vaya a recibir de su inversión a largo plazo, sino sus expectativas. A menudo éstas dependerán de la moda, de la propaganda, o de olas enteramente irracionales de optimismo o depresión. [...] No puede establecerse una regla matemática para determinar el compromiso exacto que se alcanzará entre el temor a las perdidas y el deseo de un tipo de interés elevado [...]. Posto que el riesgo que debemos tener en cuenta es el riesgo subjetivo [...] su magnitud depende en gran medida de la información relevante relativa a la inversión a la que tiene acceso. [...] La magnitud del riesgo para cualquier inversor depende, en la práctica, del grado de su ignorancia sobre las circunstancias y perspectivas de la inversión que está considerando. Sin embargo, también puede depender de lo que podemos denominar riesgo objetivo (en la medida en que lo conoce) suscitado, por ejemplo, por un gobierno ineficaz o inestable o por las incertidumbres atmosféricas (Keynes, CW, v. XV, p. 46-47 apud Skidelsky, 1983, p. 209).

Aqui devemos destacar o fato de que não somente a subjetividade concernente às probabilidades e seus respectivos pesos afetam os processos de tomada de decisões dos agentes econômicos, mas também o acesso às informações consideradas relevantes para fundamentar a tomada de decisão. Isso por sua vez, está relacionado não apenas com a forma que cada agente "lê" tais informações disponíveis e as considera no processo de tomada de decisão, mas também com as capacidades cognitivas dos agentes, com o grau de complexidade dos fenômenos cognoscíveis, com o conhecimento e a forma com que cada agente econômico percebe e se relaciona com o do mundo real, forma esta que é idiossincrática a cada agente econômico; ou seja, isto coloca a questão do problema cognitivo que está associado à capacidade individual de cada agente econômico de efetuar a "leitura" e a interpretação correta dos fenômenos socioeconômicos. Isso define, por exemplo, na visão de Keynes (1971) a diferença de posição entre os agentes bears e bulls, pois cada um, de modo idiossincrático, acessa informações e as pondera, segundo seu conhecimento e sua percepção do mundo real, para fundamentar sua tomada de decisão. Isso é tão ou mais importante quanto a questão da incerteza em relação ao futuro, pois ambos, tanto os bears quanto os bulls, agem com base na crença de que estão probabilisticamente certos em relação aos fenômenos futuros e ao comportamento da economia. Entretanto, ambos, dadas as suas idiossincrasias, destoam de forma diametralmente oposta em suas visões de mundo ${ }^{12}$.

(12) Nesta linha de argumento, destacando a crítica de Veblen à abordagem neoclássica ou tradicional sobre a natureza humana e o comportamento dos indivíduos, tem-se que o pensamento neoclássico tem por pressuposto uma "falsa concepção da natureza humana" do indivíduo, concebendo-o "equivocadamente [...] em termos hedonísticos, sendo um ente socialmente passivo, 
Institucionalistas e pós-keynesianos - ensaio sobre incerteza em uma economia capitalista financeira moderna

Destarte, é preciso reconhecer ainda que as previsões bem como a habilidade ou faculdade de "leitura" dos fenômenos econômicos e dos eventos futuros estão referenciadas na capacidade do agente "cognoscente" de apreender o objeto cognoscível - os eventos futuros e esta capacidade é determinada por fatores sociais, culturais, históricos e políticos, circunscritos nos horizontes da teoria da racionalidade limitada de Simon que se desdobra, no campo teórico, para o conceito de racionalidade processual. Tal racionalidade é definida como aquela sob a qual as ações dos agentes são analisadas não em função de preocupações maximizadoras ou otimizadoras, mas em relação à complexidade da situação estabelecida, tendo em vista não apenas a existência de informações imperfeitas, e o custo de sua obtenção, mas também a pluralidade das limitações dos indivíduos, referenciada na sua capacidade de "ler", de perceber e de, a partir daí, agir e influir sobre o contexto no qual está inserido, os critérios a serem considerados, assim como as vantagens e desvantagens levadas em consideração no processo de tomada de decisão.

Se mesmo no curto prazo torna-se difícil prever o comportamento futuro da economia, tais condições autorizam Keynes a dizer que no longo prazo estaremos todos mortos ${ }^{13}$. Pleno conhecimento e certeza absoluta quanto aos processos e eventos futuros proporcionam as condições adequadas para o funcionamento de uma economia do tipo ortodoxa em um mundo ergódico ${ }^{14}$, onde o equilíbrio é perfeitamente alcançável, deduzido a partir do comportamento maximizador e otimizador dos agentes, algo muito estranho a Keynes, ao que ele se contrapôs durante boa parte de sua vida acadêmica. É neste sentido que Davidson alega que

inerte e imutável [...]. A hipótese [neoclássica] rejeitada por Veblen de que os indivíduos são supostamente tidos como 'dados' estabelece como alternativa sua própria tentativa em construir uma 'teoria econômica evolucionária', onde instintos, hábitos e instituições exercem na evolução econômica papel análogo aos genes na Biologia [...]. Isto significa que linhas de ação habituais definem 'pontos de vistas', através dos quais os fatos e os eventos são percebidos" (Conceição, 2002, p. 89). Ou seja, deve ser destacado que a percepção dos fatos e eventos pretéritos bem como previsões sobre os fenômenos futuros é condicionada pela capacidade cognitiva de cada agente e pelo objeto cognoscível, fatores estes determinados pelo meio social, cultural e histórico no qual o indivíduo encontra-se "institucionalmente" inserido.

(13) Keynes sempre escrevia de forma satirizada e com um refinado humor, principalmente quando se reportava a seus colegas acadêmicos. Muitas das passagens de Keynes não podem ser interpretadas "ao pé da letra", como esta em destaque. Não há coisa mais óbvia e redundante que dizer que "no longo prazo" - e sabe-se lá quão longo é este prazo - "estaremos todos mortos", posto que nenhum ser humano tem o poder da imortalidade. Esta passagem em Keynes, que não foi entendida por muitos economistas e muitos "keynesianos", deve ser percebida, de um lado, como uma sátira à análise de longo prazo das abordagens clássica e neoclássica - visto que Keynes não fazia distinção entre ambas - e, de outro, como demonstrativa do comportamento de uma economia monetária de produção sobre a qual em relação aos processos e eventos futuros nada se sabe e nada podemos prever, a não ser intuitivamente. É desta forma que devemos entender o animal spirits do empresário verdadeiramente keynesiano quanto à tomada de decisão de investir. Neste sentido, a eficiência marginal do capital não dever ser entendida como um cálculo exato dos fluxos futuros de caixa, mas como receitas previstas, ou prospectivas, não exatas, em relação às quais age significativo elemento de incerteza, pois se assim não fosse estaríamos em um mundo ergódico, de concepção ortodoxo; mundo este muito estranho ao que pensava Keynes e sobre o qual se debruçou e analisou.

(14) Segundo Davidson (1996), na teoria clássica a ergodicidade era habitualmente presumida diante do pressuposto de que os agentes econômicos "possuíam presciência do futuro", enquanto que na teoria novo-clássica a ergodicidade é presumida diante do pressuposto de que os agentes econômicos têm "expectativas racionais sobre um futuro previsível e estatisticamente confiável" (Davidson, 1996, p. 33). 
Keynes argumentou que o futuro econômico é incerto, no sentido de que não pode nem ser conhecido com antecedência nem ser estatisticamente prognosticado através de sinais dos preços de mercado passado e correntes. Em termos da terminologia atual, um mundo incerto é aquele onde o axioma ergódico clássico não é aplicável. Em um ambiente não ergódico, sinais de mercado presentes e passados não oferecem informações estatisticamente confiáveis sobre eventos futuros. Em um mundo incerto (não ergódico), os lucros [...] não podem ser confiavelmente previstos a partir das informações de mercado existentes, nem ser determinados endogenamente através da função de poupanças "planejadas" de hoje. [Dessa forma], as despesas de investimentos dependem das expectativas exógenas (e, portanto, por definição, sensíveis, mas não racionais, não embasadas no axioma ergódico) dos empresários. Expectativas não ergódigas são aquilo que Keynes chamou de "animal spirits" (Davidson, 1996, p. 30).

Independentemente do caráter subjetivo das probabilidades relacionadas ao conhecimento associado aos processos e eventos futuros, que o autor denomina de "conhecimento incerto", assim como também da subjetividade relacionada ao peso ou à confiança atribuída às probabilidades usadas como guia da ação e da tomada de decisão pelos homens de negócios, Keynes destaca que

[...] a necessidade de ação e de decisão nos impele, como homens práticos, a fazer o melhor para superar este fato incômodo e nos comportarmos exatamente como deveríamos, se tivéssemos por trás um bom cálculo benthamita sobre uma série de vantagens e desvantagens futuras, cada uma multiplicada por sua devida probabilidade aguardando serem somadas (Keynes, 1937, p. 213-214).

Assentado nestes argumentos Minsky (2011) assevera, não também sem certo ar de ironia e refinado humor, que

[...] o uso de equivalente de certeza - adorado pelos acadêmicos - é, para os homens práticos, uma convenção, à qual um pretenso respeito deve ser prestado, mas que é abandonada quando surgem evidências inconsistentes com a teoria padrão. Diante da incerteza e da "necessidade de agir e tomar decisões" (QJE, p. 214), nós inventamos convenções: pressupomos que o presente é um "guia útil para o futuro" (QJE, p. 214), pressupomos que as existentes condições do mercado são boas guias para os mercados futuros e "nos esforçamos para obedecer ao comportamento da maioria ou da média" (QJE, p. 214-215) (Minsky, 2001, p. 87).

Portanto, ao relacionar certeza à convenção com base no "comportamento da maioria ou da média" das ações dos tomadores de decisões Minsky estabelece uma aproximação com o campo teórico analítico da economia institucionalista, sobretudo do "velho" institucionalismo norte-americano, ou original institutionalism, em suas matrizes teóricas de Veblen, Commons e Mitchel. Tal vertente teórica relaciona instituições a hábitos, regras e costumes coletivos enraizados ou institucionalizados. Além disso propõe que a evolução das instituições se dá com base num processo de interação cumulativa entre indivíduos/instituições e instituições/ indivíduos, entendendo por instituição "qualquer padrão organizado de comportamento coletivo, constitutivo do universo cultural" (Almeida, 1983, p. iv), mesmo que 
Institucionalistas e pós-keynesianos - ensaio sobre incerteza em uma economia capitalista financeira moderna

este padrão de comportamento coletivo leve os agentes econômicos tomadores de decisões a acreditarem em convenções estruturadas sob incerteza ou sob probabilidades subjetivas.

Estabelecidas as premissas da ação e da tomada de decisão sob condições de incerteza, Minsky (2011) concebe o comportamento de uma economia monetária financeira de produção, no sentido do que ele denomina de "capitalismo gestor do dinheiro" (Minsky, 1996). Dessa forma, afirma que

[...] é a incerteza que intervém e atenua o significado das funções de produção e das funções de preferência estáveis da teoria convencional como determinantes do comportamento do sistema. A incerteza entra fortemente na determinação do comportamento em dois aspectos: nas decisões de portfólio das famílias, das firmas e das instituições financeiras, e na opinião sustentada por firmas, pelos proprietários de ativos de capital e pelos bancos em relação às firmas no que diz respeito aos rendimentos potenciais dos ativos de capital (Minsky, 2011, p. 88).

As influências da incerteza sobre as decisões de portfólio - das famílias e empresas, mas, sobretudo, dos fundos mútuos e de pensões, nos estágio mais atual do desenvolvimento capitalista - e sobre as decisões de investir em ativos, e seu financiamento, tomadas por instituições financeiras, têm implicações profundas sobre o comportamento de uma economia monetária financeira moderna segundo a abordagem de Minsky denominada de "capitalismo gestor do dinheiro", que será abordada a seguir, destacando-se os pontos de contato desta com a abordagem do funcionamento de uma economia capitalista segundo o pensamento institucionalista.

\section{3 "Capitalismo gestor do dinheiro", aumento da incerteza e instituições}

No artigo Uncertainty and the Institutional Structure of Capitalism Economies, de 1996, último artigo do legado teórico de Minsky, o autor explicita claramente os pontos de contatos entre as visões alternativas sobre o funcionamento de uma economia capitalista monetária financeira moderna de Keynes e da economia institucionalista norte-americana ${ }^{15}$. Os pontos de contatos, segundo Minsky, decorrem da abordagem de Keynes sobre "crença" no Tratado Sobre Probabilidade que, segundo o autor,

[...] são os modelos mentais que levam a proposições sobre o comportamento do "mundo real" da economia. Essa abordagem faz com que no "mundo real" os resultados dependam de instituições. Essa abordagem sanciona intervenções do Estado para criar instituições que levam a uma economia com propriedades desejáveis. O último ato da vida de Keynes foi seu efetivo envolvimento na criação do Banco Mundial e do Fundo Monetário Internacional. Muito antes que ele [Keynes] propusesse a criação de instituições que hoje

(15) Minsky (1996) inicia o artigo com um prelúdio deixando evidente a aproximação entre as visões de mundo de Keynes e de Commons: "Carta de Keynes a John R. Commons ilustra a afinidade entre as economias de Keynes e da institucionalista americana. Essa afinidade é tão relevante agora como era quando Keynes escreveu a Commons. A atual crise de desempenho e confiança nos países capitalistas ricos torna necessário, mais uma vez, pensar sobre os pré-requisitos institucionais para o sucesso do capitalismo" (Minsky, 1996, p. 357). 
poderíamos chamar de "capitalismo com uma face humana", este já fora o grande objetivo dos institucionalistas norte-americanos (Minsky, 1996, p. 358; tradução livre).

Desta passagem podemos entender que instituições para Minsky são "crenças" ou convenções que se constituem em "modelos mentais" de comportamento dos agentes tomadores de decisões em uma economia capitalista moderna. Tais decisões, neste contexto econômico, estão relacionadas fundamentalmente com à composição e a manutenção do portfólio, ou com a aquisição de bens de capital. Mudanças na composição da carteira de portfólio e na estrutura dos bens de capital implicam necessidades e alternativas de financiamento, o que requer também tomar decisões quanto à forma de financiá-los. Dessa maneira, é perfeitamente plausível uma mediação com a abordagem institucionalista que concebe instituição como costumes, hábito e regras, e sua evolução no tempo. De outro modo, fica evidente que Minsky também concebe instituições como organizações que podem e devem ser criadas através de ações coordenadas pelo Estado e pela sociedade, para gerir, de forma mais apropriada possível, o comportamento, o desempenho e a evolução de uma economia capitalista moderna. Isso é fundamental, sobretudo, no estágio atual do "capitalismo gestor de dinheiro" "16, com sérias e profundas implicações do ponto de vista de seu comportamento instável e das magnitudes e amplitudes que as crises econômicas passaram a ter com o aprimoramento dos sistemas de informação e comunicação a nível global no estágio atual de desenvolvimento capitalista ${ }^{17}$. Nesse sentido, pode-se perceber que a abordagem de Keynes, apesar de não ser identificada como institucionalista, tem um grau elevado de proximidade com esta abordagem, em face do efetivo empenho do referido autor e de suas propostas para a criação e consolidação dos organismos internacionais instituídos no pós-Segunda Guerra Mundial, que visavam a estruturação de um sistema econômico mundial mais estável.

A sugestão de Minsky (1996) quanto ao papel da intervenção do Estado no sistema econômico, no sentido de criar instituições que promovam o desenvolvimento mais estável (menos caótico) das economias capitalistas modernas, assentadas nas propostas de Keynes de reformulação do sistema capitalista pós-Segunda Guerra, está em consonância com as proposições da abordagem dos institucionalistas que: (i) reconheciam a existência de interesses antagônicos no interior da sociedade que, para serem solucionados, defendiam reformas democráticas; e (ii) acreditavam em mudanças cumulativas e na existência de desajustes que seriam inerentes à vida econômica para o qual defendiam o planejamento econômico e a

(16) Segundo Minsky (1996) a "Tolerância pública para a incerteza é limitada. Na reestruturação do capitalismo pelo New Deal criaram-se instituições que reduziam incertezas. A evolução da economia diminuiu a eficácia das reformas do New Deal, e o capitalismo gestor de dinheiro fez aumentar radicalmente a incerteza. A criação de novas instituições econômicas que limitam o impacto da incerteza tornou-se necessário" (Minsky, 1996, p. 359).

(17) Segundo Minsky (1996), a queda nos custos de transporte e de comunicação, resultante das novas Tecnologias de Informação e comunicação (TICs), tem como consequências redução nas barreiras que protegem produtores locais. Tal fenômeno associado ao fato de que os fundos mútuos e de pensões têm por objetivo primordial a valorização do capital financeiro e atuam de forma independente do capital produtivo, alterando seus portfólios praticamente sem custos operacionais e de forma rápida, isso tem implicado em elevação no grau de instabilidade das economias capitalistas modernas e no espraiamento dos seus efeitos a nível global. Isso implica a necessidade de criação de instituições internacionais supranacionais que possam atenuar seus efeitos, visando maior estabilidade no comportamento das economias modernas. 
Institucionalistas e pós-keynesianos - ensaio sobre incerteza em uma economia capitalista financeira moderna

interferência governamental para corrigi-los. Tais proposições também assemelham-se às políticas anticíclicas preconizadas por Keynes para conter os efeitos nefastos das crises econômicas sobre a sociedade e os trabalhadores em particular.

É importante destacar as diferenças em termos dos fatores determinantes das crises econômicas nas concepções de Keynes e Minsky. Em Keynes a crise é concebida como decorrência de desajustes macroeconômicos entre a produção e demanda, em função da demanda efetiva não ser de magnitude suficiente para sustentar o nível de emprego dos fatores produtivos e, portanto, de não ser capaz de referendar as expectativas de vendas e de lucros dos empresários. Isso decorre do comportamento dos agentes de darem preferência por liquidez. De outra parte, a crise em Minsky apresenta um caráter mais sistêmico à medida que a concebe como um fenômeno inerente ao funcionamento de uma economia capitalista financeiramente desenvolvida. A crise é gestada no estágio cíclico de expansão da atividade econômica quando os agentes econômicos, sejam eles tomadores ou fornecedores de créditos, passam a assumir maior propensão ao risco, movidos pelas expectativas de ganhos. Além disso, a crise se manifesta no momento que os agentes fornecedores de crédito passam a adotar comportamento mais cauteloso diante da elevação do grau de exposição ao risco de crédito dos tomadores de empréstimos, tornando-se, portanto, agentes classificados como speculative ou Ponzi ${ }^{18}$. A forma de compreender o comportamento do sistema econômico e entender a crise em Minsky revelam outra importante mediação entre este autor e o approach institucionalista. Ambos concebem o funcionamento do sistema econômico capitalista como inerentemente instável dentro de uma trajetória evolutiva, sendo esta instabilidade resultante das relações que vão se formando entre indivíduos e instituições e de como se transmutam (ou evoluem) no tempo ${ }^{19}$. É neste sentido que devemos entender que, "as instituições não eram vistas por Veblen como algo de permanente e imutável [...] [estando] sujeitas a mudanças que acompanham o processo de evolução social" (Almeida, 1983, p xiii).

Para analisar a estrutura de uma economia capitalistas denominada de "capitalismo gestor do dinheiro", Minsky parte de uma crítica à abordagem da racionalidade limitada de Sargent (1993), ao enfatizar que apesar desta abordagem aceitar que sob expectativas racionais os agentes têm que conhecer o modelo que usam na tomada de decisões, "racionalidade

(18) Minsky classifica os agentes econômicos quanto à sua exposição ao risco em hedge que são aqueles que apresentam solvência diante dos seus passivos tanto curto quanto no longo prazo. Os agentes speculative são aqueles que apresentam dificuldades de solvência dos passivos de curto prazo, mas, por outro lado, apresentam pré-requisitos de "rolar" seus passivos no curto prazo, de forma a obter condições de rentabilidade suficiente para honrar seus compromissos financeiros no longo prazo. Os agentes classificados como Ponzi são aqueles que nem no longo prazo conseguem se tornar solventes.

(19) Conforme destaca Almeida (1983), "Veblen dava grande importância à análise do comportamento coletivo e transformações operadas. 'Toda mudança econômica é uma mudança na comunidade econômica. A mudança é sempre, e em última instância, mudanças nos hábitos e pensamentos'. Segundo ele [Veblen] o comportamento humano revelava tendências definidas que terminavam por configurar um padrão de ação coletiva, que com o tempo tornava-se uma instituição. Instituição era, pois, um conjunto de hábitos, costumes e modos de pensar cristalizados em práticas aceitas e incorporadas pela comunidade. A permanência das instituições expressava a existência de modos de pensar e de agir arraigados em grupos determinados ou em toda a sociedade" (Almeida, 1983, p. xiii). Assim, à medida que a sociedade evolui novos hábitos e novas formas de agir e de pensar vão sendo criadas e arraigadas no comportamento social, institucionalizando-se de forma perene. 
limitada" não significa, para Minsky (1996), que os agentes econômicos, em qualquer momento do tempo, não têm garantia de que estão agindo com base em modelos mutuamente consistentes - condição necessária para a existência de equilíbrio de expectativas racionais. Isto significa, em última instância, que os agentes tomadores de decisão não têm certeza sobre o grau de crença racional que é garantido pelo modelo que usam para guiar suas ações e decisões.

Como os investimentos em estoques ou em ativos duráveis das empresas capitalistas exigem financiamento externo de bancos e outras instituições financeiras, ou ainda a alavancagem através de títulos ou ações, a recorrência a recursos externos para financiá-los requer, segundo Minsky (1996), o estabelecimento de um processo de negociação entre empresários e banqueiros, forçando-os a reconhecerem que a ignorância e a conjectura agem na tomada de decisões para financiar bens de capital, cujo valor depende da visão de mercados e do retorno esperado (eficiência marginal de capital) geralmente em um horizonte de longo de tempo. Dessa forma, a incerteza que permeia a economia de Keynes e da abordagem da racionalidade limitada é decorrente, segundo Minsky (1996), da insegurança sobre a validade do modelo no qual os agentes se reportam no processo de tomada de decisão. Isto requer, segundo o autor, a adoção de medidas coordenadas de ambos os lados nas negociações, com vista a promover a suspensão de descrença. Nesse aspecto, a instituição ganha centralidade na análise na medida em que pode contribuir para arrefecer e atenuar os níveis de incerteza que poderiam predominar no sistema econômico ${ }^{20}$.

Uma questão central, segundo a abordagem institucionalista, que deve ser destacada é que do comportamento da ação coletiva dos agentes devem resultar padrões que não correspondem ao agregado das ações individuais, conforme estabelece a abordagem novoclássica de Sargent e a ortodoxia econômica do mainstream. Podemos dizer, em analogia a Marshall, que a floresta é mais do que a soma das árvores que a constitui, pois da floresta resultam muito mais benefícios (ao meio ambiente, à regularidade climática e pluviométrica, ao equilíbrio sistêmico ambiental, ao combate à redução da camada de ozônio, nãodesertificação) do que a soma agregada dos benefícios individuais de cada árvore que a compõe. Dessa forma, a ação coletiva dos agentes tomadores de decisões com bases em modelos inconsistentes pode levar a resultados espúrios, que não os asseverados pela abordagem do mainstream, como o equilíbrio ótimo paretiano resultante do comportamento racional maximizante dos indivíduos. É neste sentido que devemos entender que:

(20) A existência de contratos e de sistemas jurídicos que garante sua execução, fatores que têm aumentado sua relevância na medida em que o sistema econômico caminha para um "capitalismo gestor do dinheiro", ganha importância posto que, mais do que instituições per se, como estabelece a abordagem da Nova Economia Institucional (NEI), são fatores que alicerçam a consolidação de verdadeiras instituições, entendidas como crenças, hábitos e costumes, segundo a abordagem do velho institucionalismo. Contratos e sistemas jurídicos são "instituições" que tem como função básica contribuir para a estruturação e a consolidação de hábitos e costumes na sociedade a partir da observância às normas legais estabelecidas e institucionalizadas ao longo do tempo. 
Institucionalistas e pós-keynesianos - ensaio sobre incerteza em uma economia capitalista financeira moderna

Em Veblen a história "evolui" enquanto processo "absurdo" (absurdist), com uma trajetória "cega", inexistindo qualquer movimento dialético, que leve a rupturas preestabelecidas ou "redentoras", muito menos a qualquer processo determinístico de "progresso". Em realidade, a "cegueira" é fruto ou parte de um processo de permanente mudança e adaptação, realizada em meio à incerteza (Conceição, 2002, p. 94-95).

Como resultado desse processo de mudanças adaptativas das instituições em meio à incerteza quanto aos resultados futuros esperados, o desenvolvimento das atividades econômicas não pode ser preestabelecido, como, por exemplo, o equilíbrio a ser alcançado segundo o approach teórico da economia ortodoxa. Desse modo, Veblen concebe o processo de mudança como "uma 'sequência cumulativa de causação', mas de forma não-teleológica, o que não implica, necessariamente, progresso" (Conceição, 2002, p. 96) social ou econômico. Isto torna possível, segundo Veblen, o surgimento e a constituição de instituições que podem obstaculizar o progresso social e econômico (imbeciles instituions). Nesse sentido, Almeida (1983) destaca que

A compreensão do funcionamento do sistema econômico [em Veblen] [...] dependia do reconhecimento de que as sociedades sofriam um processo evolutivo gradual, mas permanente, que transformava o contexto em que as instituições ganhavam existência e se consolidavam (Almeida, 1983, p xiv).

No artigo de 1996, Minsky destaca que tanto em Keynes quanto na visão das expectativas racionais, os agentes necessitam apoiar-se em informações fundamentadas para além dos modelos que usam para tomar decisões, pois são egoístas e incertos em relação ao comportamento futuro da economia e devem aceitar que os outros agentes, com os quais mantém relações de interdependência, também não estejam corretos em suas próprias previsões. Isso significa dizer que os agentes precisam extrapolar os modelos que usam para além de suas experiências pessoais e de suas observações sobre o "mundo real", posto que a transformação do "mundo real" decorre não apenas dos efeitos das ações individuais, mas principalmente da ação coletiva. Isso é tão verdade quanto o fato de que crenças, hábitos e costumes não resultam meramente apenas de atos individuais em si, mas de comportamentos coletivos, sendo que é no comportamento coletivo que tais instituições são identificadas. Como a cada instante uma miríade de agentes tomam decisões independentes, a incerteza sobre os resultados decorre da incerteza que depositam no modelo que usam para orientar suas ações. Assim, os agentes não têm dúvidas apenas sobre a validade do modelo que orienta suas ações, pois sua incerteza tem implicações sobre as ações de outros atores da economia, o que torna os resultados esperados ainda mais incertos. Dessa forma, Minsky estabelece que tanto em Keynes quanto na visão da racionalidade limitada

[...] a história prévia de cada agente inclui um processo pelo qual os agentes aprendem nos moldes do modelo que usam na tomada de decisões. Em tal processo de aprendizagem, é difícil ver como a exigência de equilíbrio de expectativas racionais em todos os agentes, nos moldes do modelo, pode ser satisfeita. Quando os processos de aprendizagem são levados em consideração, os modelos que estão sendo usados para tomar decisões em 
qualquer (a cada) dia são sempre provisórios: elas nunca podem ser determinados nos moldes de um modelo definitivo (Minsky, 1996, p. 361; tradução livre).

Estabelecidas as bases conceituais para a compreensão do capitalismo gestor do dinheiro, Minsky (1996) passa a caracterizá-lo como um sistema em que (i) quase todos os negócios são organizados por corporações econômicas desenvolvidas; (ii) proporções significativas das obrigações das corporações são mantidas por instituições financeiras, como bancos e companhias de seguros, ou por fundos mútuos de investimento e de pensão; (iii) os fundos mútuos de investimentos e pensões passam a ser preponderantes na estrutura de financiamento; (iv) os fundos são obrigações vinculadas apenas por contratos, sem vínculos com os ativos físicos produtivos; (v) o objetivo explícito dos gestores dos fundos é maximizar o valor dos investimentos dos detentores de passivos, não os retornos dos bens de capitais e (vi) o desempenho de um fundo de investimento e de seus gestores é medido pelo retorno total dos ativos, dado por uma combinação de dividendos e juros recebidos e apreciação do valor por ação do portfólio.

Ao objetivar o máximo de retorno, sem qualquer compromisso em manter ações de empresas em seus portfólios, estes fundos têm proporcionado, segundo Minsky, aumento significativo na instabilidade dos sistemas produtivos, tornando "a gestão dos negócios especialmente sensível à avaliação atual de mercado das ações da empresa" (Minsky, 1996, p 364; tradução livre). Como consequência, isto tem acentuado "o caráter predador do capitalismo" e levado a "uma intensificação da incerteza ao nível da empresa". Em decorrência deste fenômeno houve, de um lado, segundo o autor, uma diminuição nos limites sociais da tolerância à incerteza que é evidenciada e tem sua contrapartida no aumento das atividades do setor de serviços de seguro e na crescente importância que esta atividade passou a ter dentro dos sistemas financeiros no estágio atual do desenvolvimento capitalista e, de outro, a ampliação do espaço e o aumento da necessidade de intervenção estatal no sentido de criar instituições que possam contribuir para diminuir o grau de incerteza na economia.

\section{Conclusão}

Conforme se procurou demonstrar, a incerteza em relação aos eventos e fenômenos econômicos futuros tem efeitos importantes e significativos sobre o comportamento dos indivíduos no sistema econômico, sendo este um conceito que permite estabelecer um link entre a escola institucionalista norte-americana e o pensamento pós-keynesiano, sobretudo na abordagem de Minsky, no que se refere ao processo de evolução de uma economia capitalista, financeiramente desenvolvida, ao papel do agente econômico inserido numa economia com estas características e à crítica ao comportamento racional maximizador do indivíduo, conforme estabelecem as vertentes teóricas ortodoxas neoclássica e novo-clássica das expectativas racionais.

Para os institucionalistas, conforme se procurou demonstrar, os indivíduos não podem ser concebidos como "dados", sendo fruto e consequência do desenvolvimento econômico das 
Institucionalistas e pós-keynesianos - ensaio sobre incerteza em uma economia capitalista financeira moderna

instituições que vão surgindo e se conformando num processo permanente e constante de evolução capitalista, econômica e social. Para esta vertente teórica, a incerteza quanto ao papel e o desempenho das instituições, que vão surgindo sob pressão das forças e fatores econômicos e sociais, pode levar ao aparecimento de instituições que mais atrapalham do que contribuem para sua evolução (imbelice institutons). Dessa forma, a evolução do sistema capitalista não necessariamente conduz a uma situação previsível de bem-estar social otimizada, de tipo que converge para situação de ótimo paretiano, conforme o approach teórico do mainstream.

Conforme se pretendeu demonstrar, para Minsky, a incerteza quanto aos eventos e fenômenos econômicos futuros em uma moderna economia capitalista financeira, que o autor denomina de "capitalismo gestor do dinheiro", cresceu de maneira significativa no estágio atual do capitalismo, exigindo cada vez mais a intervenção coordenada do Estado no sentido de criar instituições que possam amenizar seus efeitos sobre o desenvolvimento o sistema econômico. Neste sentido, existe um amplo campo de análise que pode ser desenvolvido a partir da mediação teórica de ambas as abordagens tratadas neste ensaio de forma a possibilitar um maior nível de compreensão sobre o processo de evolução do sistema capitalista de produção no seu estágio atual, cuja hegemonia é dada pelo sistema financeiro, abalado por crises sucessivas e recorrentes.

\section{Referências bibliográficas}

ALMEIDA, Maria H. T. de. Apresentação. In: VEBLEN, Thorstein. A teoria da classe ociosa: um estudo econômico das instituições. São Paulo: Abril Cultural, 1983. (Os Economistas).

BEAUD, Michael; DOSTALER, Gilles. O pensamento económico, de Keynes aos nossos dias. Porto: Edições Afrontamento, 2000.

BOYER, Robert; SAILLARD, Yves. Theórie de la régulation: l'état des savoirs. Paris, La Découverte, 1995.

BOYER, Robert; HOLLINGSWORTH, J. Rogers. How and why do social systems of production change? In: HOLLINGSWORTH, J. Rogers; BOYER, Robert. Contemporary capitalism: the embeddedness of institutions. New York: Cambridge University Press, 1997. p. $189-195$.

CARVALHO, F. C. de. Fundamentos da escola pós-keynesiana: a teoria de uma economia monetária. Rio de Janeiro, IEI/UFRJ, 1988. (Texto para Discussão, n. 176).

COASE, Ronald H. The institutional structure of production. The American Economic Review, v. 82, n. 4, p. 713-719, Sept. 1992. Disponível em: http://web.ntpu.edu.tw/ guan/courses/Coase92.pdf. Acesso em: 16 dez. 2016.

COMMONS, John R. Institutional economics. American Economic Review, v. 21, n. 4, p. 648 657, 1931. Disponível em: http://la.utexas.edu/users/hcleaver/368/368commonsoninstitutional econtable.pdf. Acesso em: 16 dez. 2016.

COMMONS, John R. Institutional economics. Madison: University of Wisconsin Press, 1934. 
Octavio A. C. Conceição, Carlos Roberto Gabriani

CONCEIÇÃO, Octavio A. C. Instituições, crescimento e mudança na ótica institucionalista. Porto Alegre: Fundação FEE, 2002.

DAVIDSON, Paul. Colocando as evidências em ordem. Ensaios FEE, v. 17, n. 2, p. 7-41, Porto Alegre, Fundação FEE, 1996.

DOSI, Giovanni. Hierarquies, Markets and Power: some foundational issues on the nature of contemporary economic organizations. Industrial and Corporate Change. v. 4, n. 1, p. 1-20, 1995.

DUGGER, William. Radical Institutionalism: Basic Concepts. Review of Radical Political Eonomics, v. 20, n. 1, p. 1-20. 1988.

FERRARI FILHO, Fernando; CONCEIÇÃO, Octavio A. C. A noção de incerteza nos póskeynesianos e institucionalistas: Uma conciliação possível? Nova Economia, Belo Horizonte, FACE/UFMG, v. 11, n. 1, p. 99-122, 2001.

GORDON, Wendell. Institutional economics: the changing system. Austin: University of Texas Press, 1980.

HICKS, John R. Keynes' theory of employment. The Economic Journal, v. 46, n. 182, p. 238253, Jun. 1936.

HICKS, John R. Mr. Keynes and the "classics": a suggested interpretation. Econometrica, v. 5, n. 2, p. 147-159, Apr. 1937.

HICKS, John R. Value and capital: an inquiry into some fundamental principles of economic theory. Oxford: Clarendom Press, 1939.

HODGSON, Geoffrey M. Institutional economics: surveying the "old" and the "new". Metroeconomica, v. 44, n. 1, p. 1-28, 1993.

HODGSON, Geoffrey M. The approach of institutional economics. Journal of Economic Literature. v. 36, n. 1, p. 166-192, Mar. 1998a.

HODGSON, Geoffrey M. On the evolution of Thorstein Veblen's evolutionary economics. Cambridge Journal of Economics. v. 22, n. 4, p. 415-431, $1998 \mathrm{~b}$.

KEYNES, John Maynard. The General Theory of Employment. Quarterly Journal of Economics. v. 51, n. 2, p 209-223, Feb. 1937.

KEYNES, John Maynard. Treatise on money. London: Macmillan, 1971. v. 1-2.

KEYNES, John Maynard. A teoria geral do emprego, do juro e da moeda. São Paulo: Nova Cultural, 1985. (Os Economistas).

KREGEL, Jean A. Aspects of a Post Keynesian theory of finance. Journal of Post Keynesian Economics. v. 21 n. 1, p. 111-133, 1998.

MARSHALL, Ray. Commons, Veblen, and other economists: remarks upon receipt of the veblen-commons award. Journal of Economic Issues, v. 26, n. 2, p. 301-322, Jun. 1993. 
Institucionalistas e pós-keynesianos - ensaio sobre incerteza em uma economia capitalista financeira moderna

MATTHEWS, R. C. O. The economics of institutions and the sources of growth. The Economic Journal, v. 96, p. 903-918, Dec. 1986.

MINSKY, Hyman P. Estabilizing an instable economy. New York: McGraw Hill, 1986.

MINSKY, Hyman P. Uncertainty and the institutional structure of capitalism economies. Journal Economics Issues, v. XXX, n. 2, p. 357-368, 1996.

MINSKY, Hyman P. John Maynard Keynes. Campinas: Editora da Unicamp, 2011.

MITCHELL, Wesley C. Os ciclos econômicos e suas causas. São Paulo: Abril Cultual, 1984. (Os Economistas).

MYRDAL, Gunnar. Aspectos políticos da teoria econômica. São Paulo: Abril Cultural, 1984. (Os Economistas).

NELSON, Richard R.; WINTER, Sidney G. An evolutionary theory of economic change. Cambridge, Massachusetts: Harvard University Press, 1982.

NORTH, DOUGLASS. Economic performance through time. The American Economic Review, v. 84, n. 3, p. 359-68, Jun. 1994.

SAMUELS, Warren J. The present state of institutional economics. Cambridge Journal of Economics, v. 19, n. 4, p. 569-590, 1995.

SARGENT, Thomas J. Bounded rationlality in macroeconomics. Oxford: Clarendon Press, 1993.

SKIDELSKY, Robert. John Maynard Keynes - 1. Esperanzas frustradas: 1883-1920. Madrid: Alianza Editorial, 1986.

VEBLEN, Thorstein. The place of science in modern civilization and other essays. New York: Huebsch, 1919.

VEBLEN, Thorstein. Why is economics not an evolutionary science? Cambridge Journal of Economics, v. 22, p. 403-414, 1998.

VEBLEN, Thorstein. A teoria da classe ociosa: um estudo econômico das instituições. São Paulo: Abril Cultural, 1983. (Os Economistas).

VILLEVAL, Marie-Claire. Une théory économique des institutions. In: BOYER, R. et SAILLARD, Yves. Théorie de la régulation: 1'état des savoirs. Paris: La Découverte, 1995.

WILLIAMSON, Oliver E. Mercados y Jerarquías: su análisis y sus implicaciones antitrust. México D. F.: Fondo de Cultura Económica, 1991a.

WILLIAMSON, O. E. Comparative economic organization: the analysis of discrete structural alternatives. Administrative Science Quarterly, v. 36, n. 2, p. 269-296, Jun. 1991b.

WILLIAMSON, Oliver E. Hierarquies, markets and power in the economy: an economic perspective. Industrial and Corporate Change, v. 4, n. 1, p. 21-49, 1995.

ZYSMAN, John. How institutions create historically rooted trajectories of growth. Industrial and Corporate Change, v. 3, n. 1, p. 243-283, 1994. 